Research Article

\title{
Evolution of Microstructure and Microsegregation of Ti-45Al-8Nb Alloy during Directional Solidification
}

\author{
Xiangjun Xu $\mathbb{D}^{1},{ }^{1}$ Rui $\mathrm{Hu}^{2}$ Junpin Lin $\mathbb{D}^{3},{ }^{3}$ and Jian Guo ${ }^{4}$ \\ ${ }^{1}$ School of Materials Science and Engineering, Yangtze Normal University, Chongqing 408100, China \\ ${ }^{2}$ State Key Laboratory of Solidification Processing, Northwestern Polytechnical University, Xi'an 710072, China \\ ${ }^{3}$ State Key Laboratory for Advanced Metals and Materials, University of Science and Technology Beijing, Beijing 100083, China \\ ${ }^{4}$ Materials and Chemistry School, Zhongyuan University of Technology, Zhengzhou 450007, China \\ Correspondence should be addressed to Xiangjun Xu; drxxj@126.com
}

Received 4 July 2018; Accepted 2 September 2018; Published 8 October 2018

Academic Editor: David Holec

Copyright ( $\odot 2018$ Xiangjun Xu et al. This is an open access article distributed under the Creative Commons Attribution License, which permits unrestricted use, distribution, and reproduction in any medium, provided the original work is properly cited.

\begin{abstract}
High $\mathrm{Nb}$-containing TiAl alloys have good oxidation resistance and mechanical properties, but the microstructure and the properties are substantially affected by the segregation. To quantitatively investigate the segregation behavior of Al during solidification, microstructures of directionally solidified (DS) Ti-45Al-8Nb (in atomic percent) alloy prepared at withdrawing rates of $30 \mu \mathrm{m} / \mathrm{s}$ and $200 \mu \mathrm{m} / \mathrm{s}$ and a temperature gradient of $4200 \mathrm{~K} / \mathrm{m}$ were observed by optical microscope and electronic probe microanalyzer. The microsegregations were characterized by wave dispersive spectroscopy. The results show that the DS ingots include the no melting zone, directionally solidified zone with columnar grains, mushy zone, and quenched liquid zone. The primary dendritic arm spacings are $353 \mu \mathrm{m}$ and $144 \mu \mathrm{m}$, respectively, for the two ingots. But the solidified microstructures of the ingots are large lamellar colonies, which contain a few $\mathrm{B} 2$ patches and $\gamma$ bands induced by microsegregation. From dendritic zone to columnar zone, the volume fractions of $\mathrm{B} 2$ patches and $\gamma$ bands decrease. The segregation extents of $\mathrm{Al}$ and $\mathrm{Nb}$ decrease with the increase of solidification rate. There exists an obvious back diffusion process of Al during solidification and cooling after solidification. According to evolution of $\mathrm{Al}$ concentration profiles from mushy zone to columnar grain zone, interdiffusion coefficient for $\mathrm{Al}$ in $\beta$-Ti at near solidus temperature is semiquantitatively calculated, and the value is $(6-11) \times 10^{-11} \mathrm{~m}^{2} / \mathrm{s}$.
\end{abstract}

\section{Introduction}

High Nb-containing TiAl alloys have garnered increasing attention due to their excellent properties, which are superior to those of conventional TiAl alloys, especially at high temperatures [1-6]. For example, the yield strength of Ti$45 \mathrm{Al}-8 \mathrm{Nb}$ alloy with fully lamellar structure is $505 \mathrm{MPa}$ at $900^{\circ} \mathrm{C}$ because $\mathrm{Nb}$ increases Peierls stress of lattice and the interaction between dislocations and improves the high temperature stability of microstructure of the TiAl alloys [1]. The oxidation behavior of TiAl alloy is significantly improved by $\mathrm{Nb}$ addition. Pentavalent niobium ion could substitute for tetravalent titanium ion in $\mathrm{TiO}_{2}$ oxide. The (Ti, $\mathrm{Nb}) \mathrm{O}_{2}$-rich layer is dense and chemically uniform, which is more protective than the $\mathrm{TiO}_{2}$ layer [6]. So this kind of TiAl alloys has been developed over the past twenty years and is beginning to use in both automotive and aerospace industries $[7,8]$. However, microsegregation of $\mathrm{Al}$ and $\mathrm{Nb}$ elements can be easily induced in the castings of the alloys. It is known that the microstructure and the mechanical properties are very sensitive to the $\mathrm{Al}$ content for TiAl alloys [9], and the volume fraction of $\mathrm{B} 2$ and $\omega$ phases is sensitive to $\mathrm{Nb}$ content for high $\mathrm{Nb}$-containing TiAl alloys $[10,11]$. Thus, reducing and eliminating the microsegregation in casting are necessary for obtaining optimal properties for high Nb-containing alloys. A thorough understanding of evolution of microstructure and microsegregation during solidification should be of great importance for prediction of material properties and for design of postcasting heat treatment processes. Microstructures of Ti-Al-Nb ternary alloys have been studied by many groups. For example, Shuleshova et al. have in situ observed the primary phase of $15 \mathrm{Ti}-\mathrm{Al}-\mathrm{Nb}$ alloys by synchrotron radiation [12]; Ding et al. have analyzed $L+\beta \longrightarrow \alpha$ peritectic reaction of 
Ti-46Al-5Nb and Ti-45Al-6Nb-0.3B alloys and prepared single lamellar grain with lamellar boundaries parallel to the ingot growth direction by double directional solidification [13]; Oering et al. and Klein et al. have studied $\beta \longrightarrow \alpha$ transformation of Ti-45Al-(5-7) Nb-(0.5-1) Mo-(0-0.2)B alloys and TNM alloy, respectively $[14,15]$. However, there is scarce work quantitatively reported on the microsegregation behavior of high $\mathrm{Nb}$-containing TiAl alloys as yet, especially on the element distribution and microsegregation evolution during solidification and cooling processes [16, 17]. The present work will investigate the microstructures and compositions of directionally solidified (DS) Ti-45Al-8 $\mathrm{Nb}$ (in atomic percent) alloy in order to clarify the microsegregation evolution behavior and its effect on the microstructure during solidification and cooling procedures.

\section{Experimental}

The $1 \mathrm{~kg}$ button ingot with nominal composition of Ti$45 \mathrm{Al}-8 \mathrm{Nb}$ was prepared by nonconsumable arc melting (tungsten electrode) of the high purity elements, that is, Ti (99.99 wt.\%), Al (99.99wt.\%), and Nb (99.99wt.\%), using a water-cooled copper hearth in a gettered ultra-high-purity argon atmosphere. With the inert gas fusion infrared method, we tested the oxygen content of the ingot, and the value was $360 \mathrm{ppm}$. The rods with each dimension of $\Phi 6.8 \times 100 \mathrm{~mm}$ were cut from the button ingot using electric spark machining for DS processes. The rod was inserted in a $\Phi 8 \times 126 \mathrm{~mm}$ dense cylindrical alumina crucible covered with a $0.3 \mathrm{~mm}$ thick layer of yttria to keep alloy from reacting with the crucible and mounted in a modified Bridgman-type apparatus (Figure 1). Two DS processes are performed at a thermal gradient of $4.2 \mathrm{~K} / \mathrm{mm}$ and withdrawing rates of $30 \mu \mathrm{m} / \mathrm{s}$ and $200 \mu \mathrm{m} / \mathrm{s}$, respectively. After withdrawing $50 \mathrm{~mm}$, the ingots were quenched to capture the morphologies of the dendrites.

The solidified ingots were firstly cut longitudinally. Half of each ingot was metallographically polished and etched to observe macrostructure using an OLYMPUS-BX51M optical microscope. Two transverse sections in each ingot, corresponding to the mushy zone and fully solidified zone, respectively, which are $5 \mathrm{~mm}$ apart, were positioned from the observed half and cut from another half of the ingot. The four transverse sections were mounted into bakelite puck and metallographically polished. Then, they were analyzed with a JEOL JXA-8230 electron microprobe (EPMA) equipped with four wavelength dispersive spectrometers (WDS) and one back-scattered electron (BSE) detector. An area-scan method was adopted to determine the microsegregation behavior of each transverse section. 121 points within an area of $400 \times 400 \mu \mathrm{m}$ on each section, which encompassed more than one primary dendrite arm, were measured the compositions automatically. After collecting the data, regardless of their sampling locations, $\mathrm{Al}$ series is arranged into ascending order and $\mathrm{Nb}$ series is arranged into descending order obeying rank number from 1 to 121 . Then, each $\mathrm{Al}$ (applied equally to $\mathrm{Nb}$ ) is assigned to a fraction solid. A fraction solid $f_{\mathrm{s}}$ at rank number, $R_{\mathrm{i}}$, is the ratio of $R_{\mathrm{i}}$ to the total number of sampled points, 121. Finally, continuous

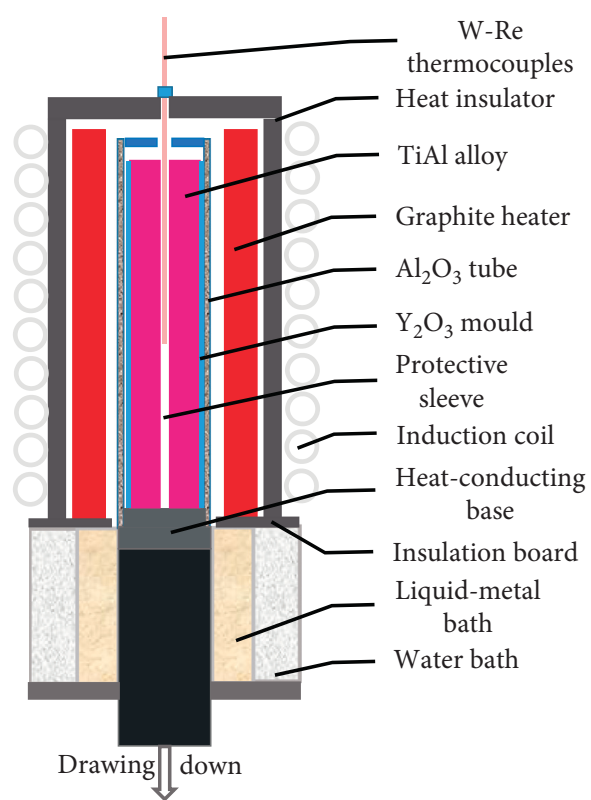

FIgURE 1: Schematic diagram of the modified Bridgman-type apparatus.

composition profiles for $\mathrm{Al}$ and $\mathrm{Nb}$ elements were produced. The principle of constructing composition profiles is expounded in Reference [18]. Some sections were observed on a Tecnai G2 F30 transmission electron microscope (TEM) to reveal microstructural details. Foil samples for the TEM experiment were mechanically ground to $50 \mu \mathrm{m}$ and subsequently thinned by twin-jet polishing in an electrolyte containing $30 \mathrm{ml}$ perchloric acid, $175 \mathrm{ml}$ butyl alcohol, and $300 \mathrm{ml}$ methanol at $30 \mathrm{~V}$ and $-30^{\circ} \mathrm{C}$.

\section{Results and Discussion}

3.1. Macrostructures of the DS Ingots. Each DS ingot includes 4 zones, which we designate the no melting zone, columnar DS zone, mushy zone, and quenched zone. The no melting zone with original nearly lamellar $(\mathrm{NL})$ microstructure is the bottom part of the ingot, which is on the top of the withdrawing rig. Because the withdrawing rig is in Ga-In-Sn liquid metal within water-cooled copper die, the bottom part of the rod is nearly at room temperature and cannot be melted during heating. With the increase of the distance from the bottom of the rod, the rod was heated to $\alpha$ phase region and the grains grew up, forming a coarse-sized fully lamellar (FL) microstructure after cooling to room temperature. Upon this zone, the rod melts in the crucible. By withdrawing the crucible and the rod, the melt was cooled and DS ingot formed. Figure 2 is part of macrostructure of the longitudinal section of the $30 \mu \mathrm{m} / \mathrm{s}$ withdrawn DS ingot. The left of the image is oriented to the bottom of the ingot and the heat extraction direction. It is a columnar structure with the preferential growth direction nearly parallel to axis of the ingot, showing coarsening of the primary dendrite arms and disappearance of the secondary dendrite arms for holding at high temperature after solidification. Above the columnar grain, the mushy zone appears typical dendrite 


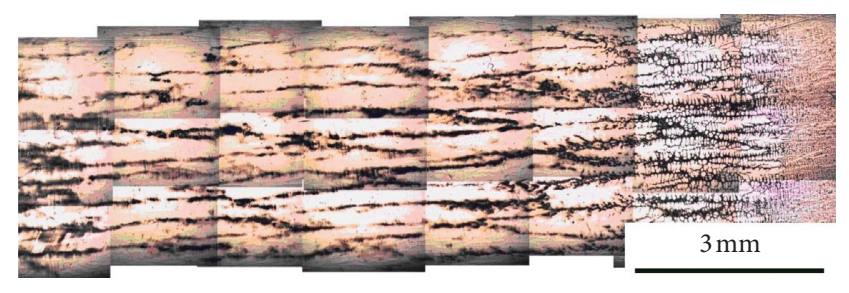

FIgURE 2: The macrostructure of part of the $30 \mu \mathrm{m} / \mathrm{s}$ withdrawn DS ingot showing the columnar structure (left) and dendritic structure (right).

microstructure, coexisting with the quenched microstructure in the interdendritic zone. The $200 \mu \mathrm{m} / \mathrm{s}$ withdrawing DS sample has the similar macrostructure. The distinct difference of the two ingots is the primary arm spacing, which is $353 \mu \mathrm{m}$ for the $30 \mu \mathrm{m} / \mathrm{s}$ withdrawn DS ingot and $144 \mu \mathrm{m}$ for the $200 \mu \mathrm{m} / \mathrm{s}$ withdrawn DS ingot.

3.2. Microstructure Evolution. Figure 3 is the microstructures of the mushy zone of the $30 \mu \mathrm{m} / \mathrm{s}$ withdrawing DS ingot obtained by observing the transverse section (named section 30-1 hereafter). Secondary dendrite arms are oriented at an angle of $90^{\circ}$ to each other. Besides well-developed secondary arms, tertiary dendrite arms orientated at an angle of $90^{\circ}$ to the secondary arms can also be clearly identified (Figure 3(a)). According to the $8 \mathrm{Nb}$ containing Ti-Al quasiphase diagram and the fourfold symmetry of dendrites, it is concluded that primary solidification phase is $\beta$ phase. This is in accordance with the results of Shuleshova, which were drawn after in situ observation by synchrotron radiation and showed that the alloys with $43.5-46.4 \mathrm{Al}$ and about $8 \mathrm{Nb}$ completely solidified with single $\beta$ as the primary phase [12]. Higher-magnification BSE images of transverse section in mushy zone show that the composition of a dendrite does not transit from the spine to the edge, but Nb-rich (white contrast) networks with a width of $1-4 \mu \mathrm{m}$ distribute in grey contrast matrix (Figure 3(b)). TEM analysis indicates that the grey matrix in Figure 3(a) is $\gamma / / \alpha_{2}$ lamellar colonies, whereas the network is B2 phase (Figure 3(c)). It is clear that even quenching procedure cannot restrain $\beta \longrightarrow \alpha+\beta$ and $\alpha \longrightarrow \gamma+\alpha_{2}$ transformations, and $\mathrm{Nb}$ element undergoes distinguishable redistribution through $\beta \longrightarrow \alpha+\beta$ transformation. During $\beta \longrightarrow \alpha+\beta$ transformation, the Al diffuses into $\alpha$ phase, while the $\beta$ stabilization element $\mathrm{Nb}$ diffuses to opposite direction. This tendency leads to enrichment of $\mathrm{Nb}$ and depletion of $\mathrm{Al}$ at the interfaces between $\beta$ and $\alpha$ phases. Finally, the untransformed $\beta$ area or the boundaries between transformed $\alpha$ grains abound in $\mathrm{Nb}$. These zones evolve into B2 phase during quenching at higher cooling rate [19]. This is also identified by TEM selected area electron diffraction (SAD) pattern of these zones (Figure 3 (d)).

Figure 4 shows the microstructure of columnar zone of the $30 \mu \mathrm{m} / \mathrm{s}$ withdrawing DS ingot by observing a transverse section $5 \mathrm{~mm}$ below that shown in Figure 3 (named section 30-2 hereafter). Though the secondary arms and the tertiary arms disappear, the primary arms are delineated by the $\mathrm{Al}$ rich lines with dark contrast. Also the white vermiform bands rich in $\mathrm{Nb}$ are obvious. Compared with Figure 3(a), the density of the white bands is sparse and the width of the bands is thick (Figure 4(a)). Higher-magnification image shows most of the white bands and the black lines are lamellar structures (Figure 4(b)). Very few patches in the white bands are $\mathrm{B} 2$ and limited black lines are $\gamma$ phase. The columnar zone also undergoes $\beta \longrightarrow \alpha+\beta$ transformation, and this process is a near-equilibrium process at the present growth rate. Thus, $\alpha$ grains have enough time to grow up and engulf many original $\mathrm{Nb}$-rich $\alpha$ grain boundaries or Al-rich dendrite boundaries, leading to coarse-sized lamellar colony containing vermiform bands with different contrasts. Also it has enough time for elements to diffuse and redistribute, leading to a less extent of microsegregation. This will be characterized semiquantitatively in Section 3.3.

Figure 5 shows the BSE images of transverse sections corresponding to the mushy zone and the columnar zone of the $200 \mu \mathrm{m} / \mathrm{s}$ withdrawn ingot (named section 200-1 and section 200-2, respectively, hereafter). The morphology of the mushy zone is similar to that of section 30-1, except for the two aspects: (1) the dendrites are more typical and clear dendritic arms are observed, and (2) the primary and secondary arm spacings are decreased (Figure 5(a)). The primary arm spacing is $144 \mu \mathrm{m}$. These are normal phenomena, because the microstructure of the mushy zone exhibits a cellular-dendritic structure at lower growth rate and a typical dendritic morphology at higher growth rate [20] and dependence of primary dendritic arm spacing on growth rate obeys $\mathrm{kv}^{-1 / 4}$ relationship, where $k$ is a constant and $v$ is the solidification rate [21]. Analogously, dependence of secondary dendritic arm spacing on growth rate obeys $M v^{-1 / 3}$ relationship, where $M$ is a constant and $v$ is the solidification rate [22]. Fine dendritic arm spacing for the ingot with higher growth rate is beneficial for eliminating the microsegregation by heat treatments because the annealing time required to homogenize is proportional to the square of dendritic arm spacing [23]. High-magnification image also shows that Al-rich bands with black contrast are $\gamma$ phase and $\mathrm{Nb}$-rich nets with bright contrast are B2 phase. Lowmagnification BSE images of section 200-2 show that outline of primary dendrite disappears. The trace of $\mathrm{Al}$ in interdendritic zone is hardly discerned. The Nb-rich zones show white needle morphology with several millimeters long or a network morphology with the mesh of about $100 \mu \mathrm{m}$. Why $\mathrm{Nb}$ distributes in such forms is not clear. Highmagnification images show that section 200-2 is also fully lamellar structure with few B2 phase. The $\alpha$ grains in section 200-2 are lathy morphology (Figures 5(c) and 5(d)), quite different from the equiaxed morphology in section 30-2 (Figure 4). So, at higher cooling rate, $\alpha$ plates precipitating from $\beta$ grain boundaries form a Widmannstätten-type structure. This structure is also found by Oering et al. in Ti-45Al-(5-7)Nb-(0.5-1)Mo-(0-0.2)B alloys [14]. Klein et al. quantitatively studied this phenomenon in TNM alloy and pointed out that low cooling rates rendered equiaxed $\alpha$ grains, whereas high cooling rates led to the formation of lath-like (Widmannstätten) structures [15]. At various cooling rates, growth up and annexation of $\alpha$ grains are so conspicuous that fully lamellar colonies with large size form. 

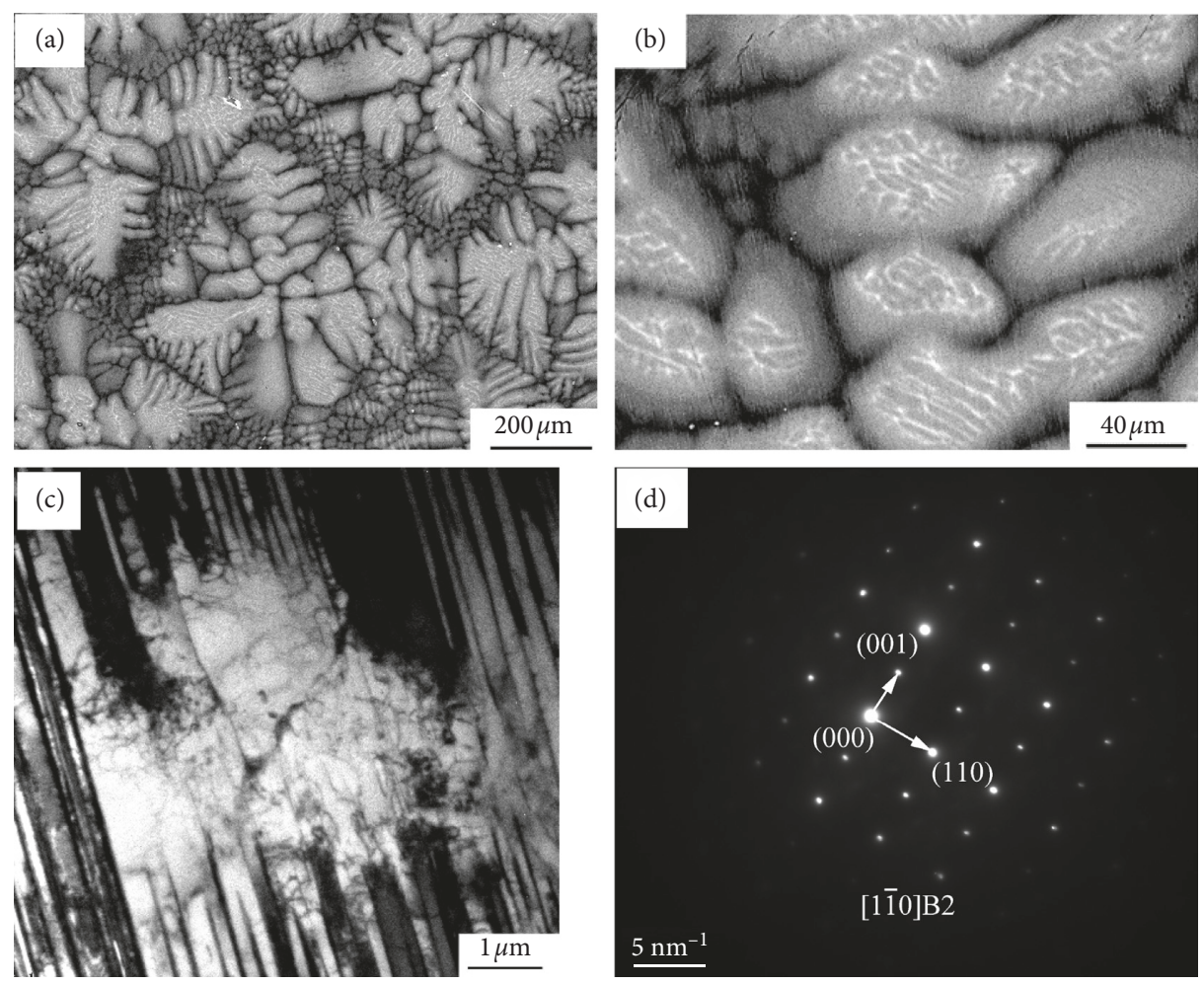

FIgURE 3: Microstructures of transverse section of the mushy zone for the $30 \mu \mathrm{m} / \mathrm{s}$ withdrawn DS ingot: (a) low-magnification BSE image; (b) high-magnification BSE image; (c) TEM image of the white zone in (b); (d) SAD pattern of B2 phase in (c).
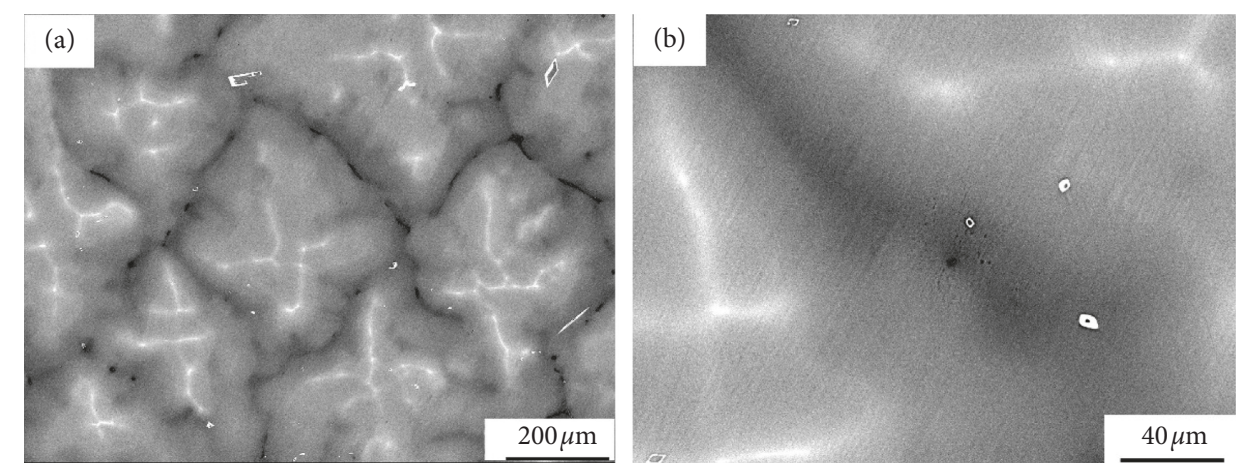

FIgURE 4: Microstructure of the transverse section of the columnar zone for the $30 \mu \mathrm{m} / \mathrm{s}$ withdrawn DS ingot: (a) low-magnification BSE image; (b) high-magnification BSE image.

3.3. Microsegregation Evolution. Figure 6 shows the measured concentration profiles of $\mathrm{Al}$ and $\mathrm{Nb}$ in section 30-1 and section 200-1, representing the mushy zone, and in section 30-2 and section 200-2, representing the columnar grains zone. For comparing and easily identifying microsegregation behavior, the concentration profiles are arranged in different ways. Figure 6(a) is the $\mathrm{Al}$ concentration profiles in section $30-1$ and section $200-1$. It is obviously seen that the segregation extent is severer in section $30-1$ than in section 200-1, and microsegregation ratios of $\mathrm{Al}$ (the ratio of the maximum $\mathrm{Al}$ content to the minimum $\mathrm{Al}$ content) for the two mushy zones are 1.19 and 1.15 , respectively. The differences of the maximum and the minimum $\mathrm{Al}$ contents in section $30-1$ and section $200-1$ are 8.48 at.\% and 6.49 at.\%, respectively. The concentration profiles of $\mathrm{Nb}$ are shown in Figure 6(b). For the differences of the maximum and minimum $\mathrm{Nb}$ contents, the trend of decrease with the increase of the solidification rate is not found. This is maybe because B2 and $\gamma$ phases affect the test results of $\mathrm{Nb}$ content. Even so, it is concluded that the distribution of alloy elements in dendritic structure formed at high solidification rate is more uniform than that in dendritic structure formed at low withdrawing rate. This results from the difference of the dendritic arm spacing. The dendrite has a finer arm spacing that induced three effects: (1) the solute is hard to accumulate between finer spacing 

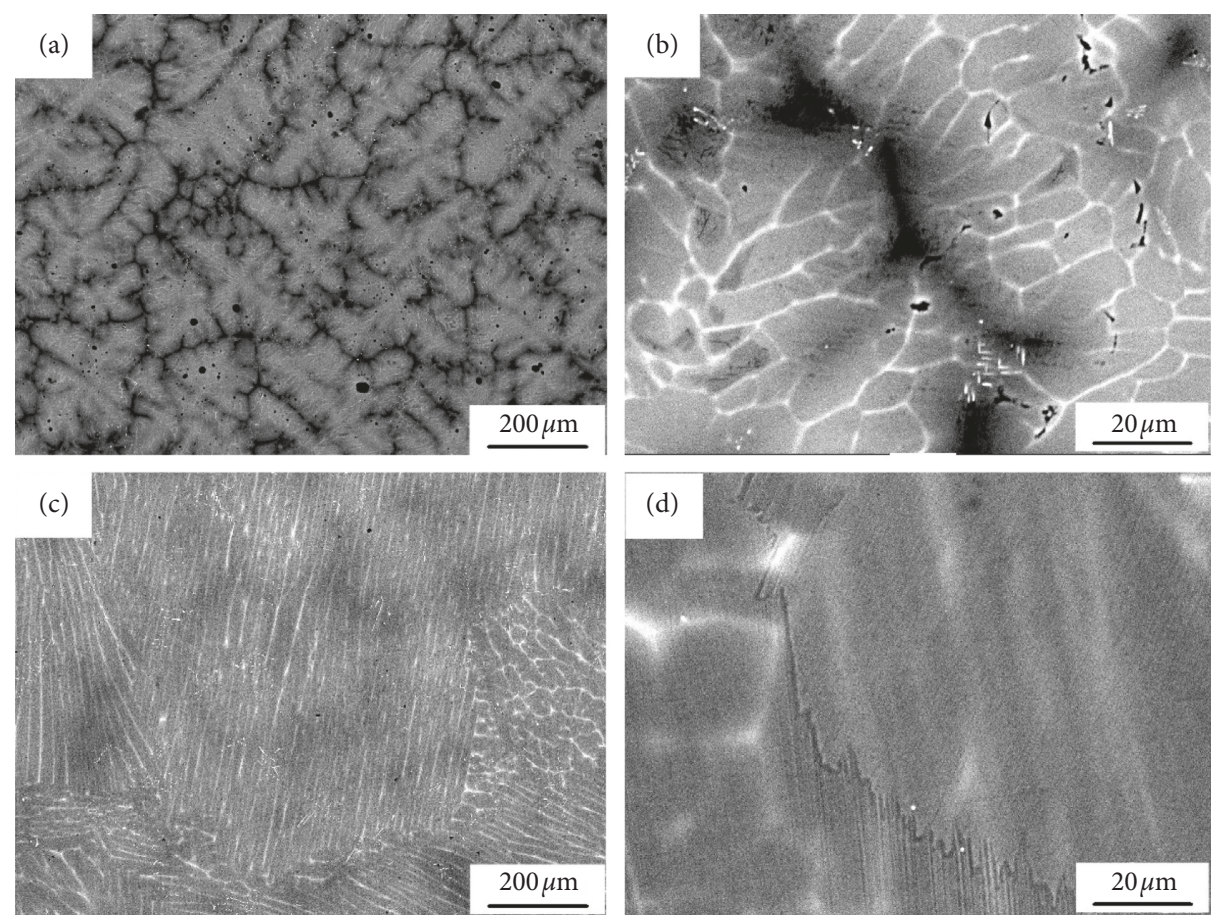

FIGURE 5: BSE images of transverse sections of the $200 \mu \mathrm{m} / \mathrm{s}$ withdrawn DS ingot: $(\mathrm{a}, \mathrm{b})$ the mushy zone at low and high magnifications; (c, d) columnar zone $5 \mathrm{~mm}$ below the mushy zone at low and high magnifications.

arms for the larger solid/liquid interface; (2) easy impinging of solute fields in the solidification fronts of two arms increases the concentration gradient in liquid; and (3) the permeability of the interdendritic channels is low, convective mass flow in the liquid is hindered, and boundary layer is constructed before the solid/liquid interface [24]. These factors are beneficial for strong accumulation of $\mathrm{Al}$ in the liquid at the solid/liquid interface, thus leading to $\mathrm{Al}$ backdiffusion in solid and increase of $\mathrm{Al}$ content in the solid and uniform element distribution within longer fraction solid.

Figure 6(c) shows the $\mathrm{Al}$ concentration profiles in section 30-2 and section 200-2. As in Figure 6(a), segregation extent is severer in section 30-2 than in section 200-2, and the microsegregation ratios of $\mathrm{Al}$ for these two sections are 1.10 and 1.04, respectively. The differences of the maximum and the minimum $\mathrm{Al}$ contents in section 30-2 and section 200-2 are 4.26 at.\% and 1.83 at.\%, respectively. This trend is also shown in Figure 5(d), the $\mathrm{Nb}$ concentration profiles in these two sections. The distinguishable $\mathrm{Nb}$ segregation in these two sections is attributed to the scarce of B2 and $\gamma$ blocks, whose compositions cannot be acquired by WDS to cover up the truth. Segregation ratios of $\mathrm{Nb}$ (ratio of the maximum $\mathrm{Nb}$ content to the minimum $\mathrm{Nb}$ content) in section 30-2 and section 200-2 are 1.45 and 1.27. By comparing the $\mathrm{Al}$ or $\mathrm{Nb}$ concentration profiles from the two sections of the same ingot, it is worthy to note that segregation extent obviously decreases during solidification and microstructure evolution. The segregation ratios of $\mathrm{Al}$ decrease from 1.19 of mushy zone to 1.10 of columnar zone in the $30 \mu \mathrm{m} / \mathrm{s}$ withdrawn ingot (Figure 6(e)) and from 1.15 of mushy zone to 1.04 of columnar zone in the $200 \mu \mathrm{m} / \mathrm{s}$ withdrawn ingot (Figure 6(f)).
Figures 6(e) and 6(f) also show the calculated concentration profiles of $\mathrm{Al}$, which is based on the thermodynamic database of Witusiewicz using Pandat software [25]. At present, the calculation can only be made for the Scheil model, which is based on the assumptions of complete mixing in the liquid but no diffusion in the solid. The concentration profiles of $\mathrm{Al}$ in the two sections of each ingot deviate from the calculated result, that is, actual $\mathrm{Al}$ distribution is more uniform than the $\mathrm{Al}$ distribution predicted by the Scheil equation. This indicates that the back diffusion of $\mathrm{Al}$ upon solidification cannot be ignored. The above continuous composition profiles are produced by assuming that the solid concentration varies continuously with fraction solid. However, the element partition associated with $\beta \longrightarrow \alpha+\beta$ transformation is opposite to the element partition during solidification. Though the redistribution can be seen, this is hard to be tackled and neglected in the construction of concentration profiles. Even so, it is concluded that back diffusion of $\mathrm{Al}$ is an incessant and considerable process during solidification of high $\mathrm{Nb}$-containing TiAl alloys. So, if we analyze and calculate the element distribution during solidification, using Scheil mode or ignoring back diffusion of $\mathrm{Al}$ is not reasonable. The smaller the primary arm spacing, the more prominent the back diffusion of $\mathrm{Al}$.

\subsection{Interdiffusion Coefficient for $A l$ in $\beta$-Ti at near Solidus} Temperature. Comparing the microsegregation extent of $\mathrm{Al}$ or Nb in mushy zones (section 30-1 and section 200-1) and that in columnar zones (section 30-2 and section 200-2), one can say that solidified ingots are subjected to a homogenization heat treatment during the withdrawing processes. The evolution of $\mathrm{Al}$ concentration profiles from mushy zone to 


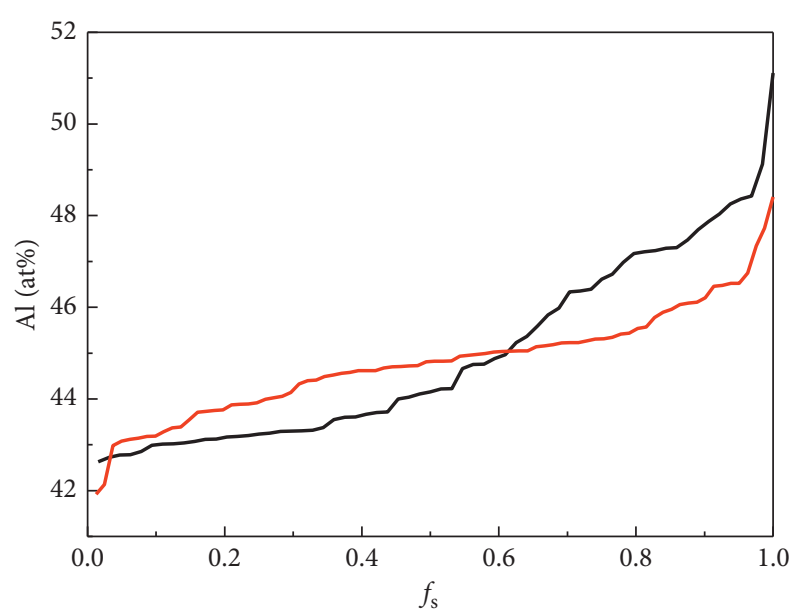

- Section 30-1

— Section 200-1

(a)

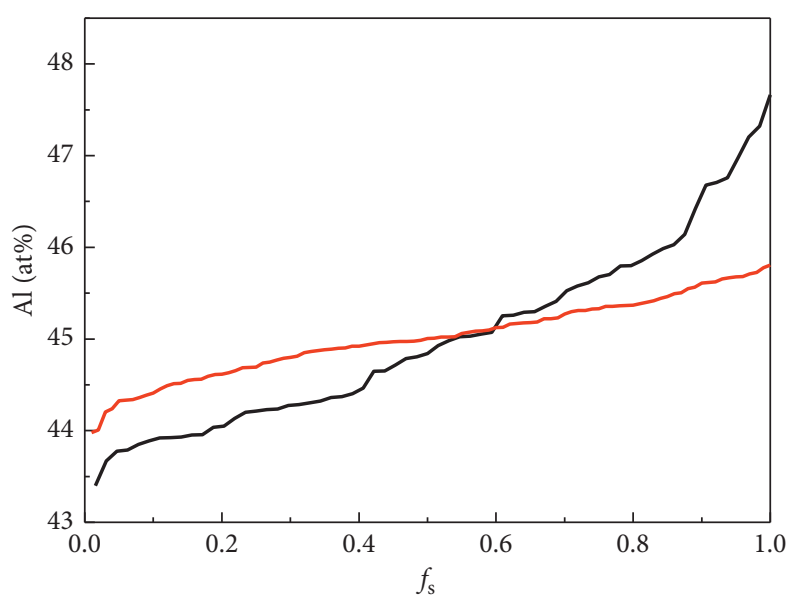

- Section 30-2

- Section 200-2

(c)

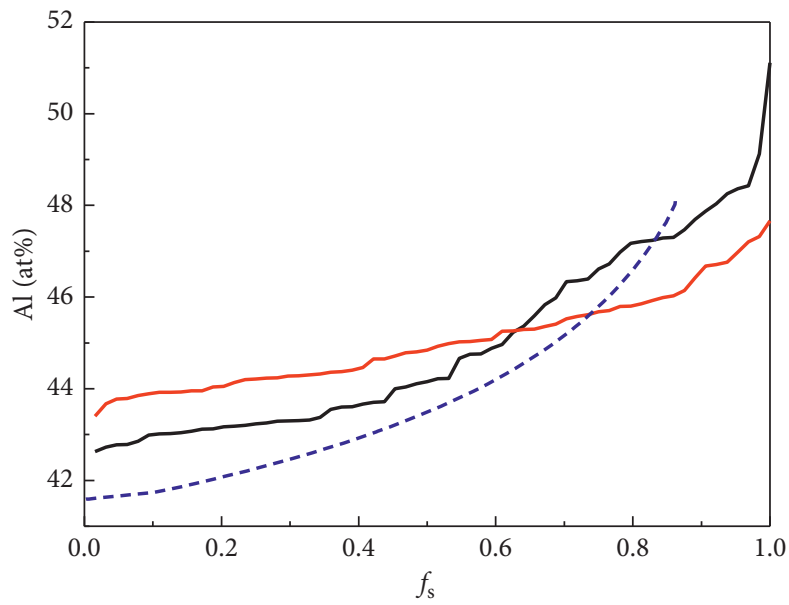

- Section 30-1

- Section 30-2

- - - Calculated result

(e)

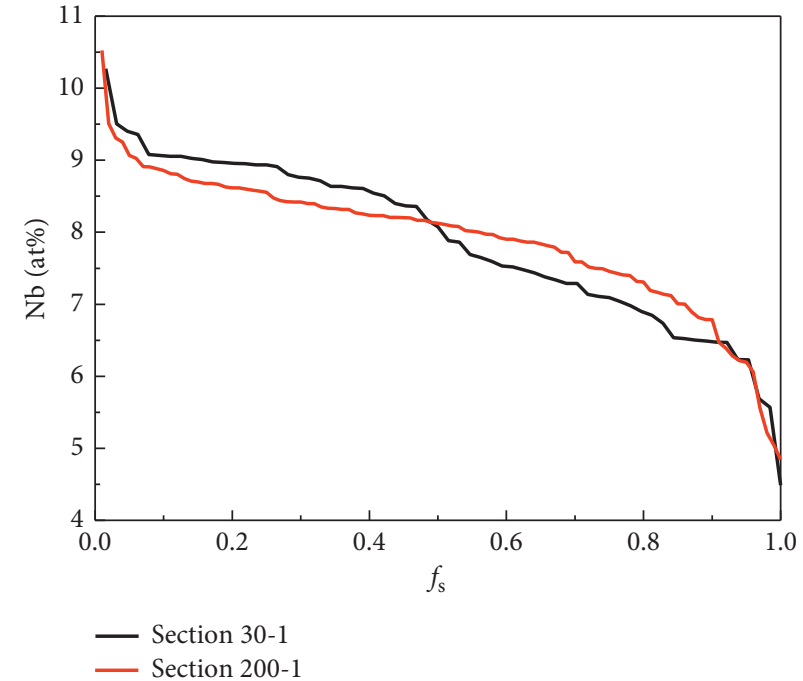

(b)

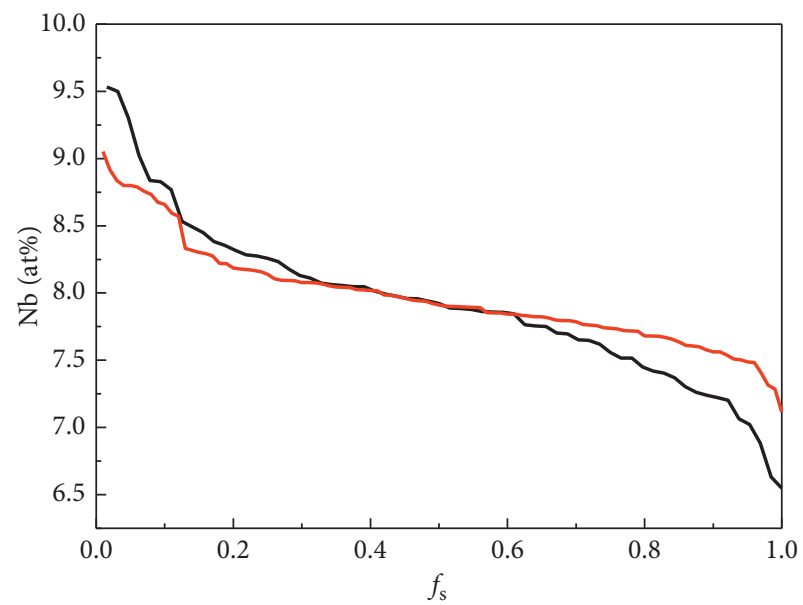

Section 30-2

Section 200-2

(d)

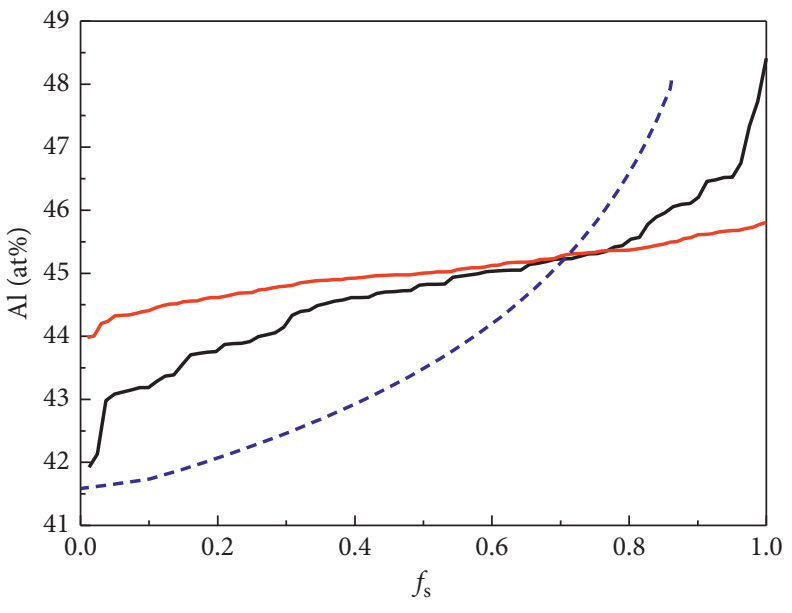

Section 200-1

- Section 200-2

- - - Calculated result

(f)

FIGURE 6: Measured concentration profiles as a function of solid fraction: (a) Al in mushy zone; (b) Nb in mushy zone; (c) Al in columnar zone; (d) $\mathrm{Nb}$ in columnar grains; (e) $\mathrm{Al}$ in the two sections of $30 \mu \mathrm{m} / \mathrm{s}$ withdrawn ingot; (f) $\mathrm{Al}$ in the two sections of $200 \mu \mathrm{m} / \mathrm{s}$ withdrawn ingot. 
columnar grain zone can be thought as a result of homogenization of $\mathrm{Al}$ interdendritic segregation for diffusion in $\beta$-Ti. The interdiffusion coefficient for $\mathrm{Al}$ in $\beta$-Ti $\left(D_{\mathrm{s}}\right)$ at near solidus temperature can be semiquantitatively calculated from the concentration profiles.

In order to determine the homogenization of the $\beta$-Ti occurred during its solidification and cooling, only one dendrite arm needs to be considered for the periodical element distribution (the cycle is primary arm spacing $\lambda$ ). The $\mathrm{Al}$ concentration profiles in section 30-2 and section 200-2 evolved from those in section 30-1 and section 200-1 after $167 \mathrm{~s}$ and $25 \mathrm{~s}$, respectively. The times are obtained by the quotients of the distance of the two sections $(5 \mathrm{~mm})$ and drawing rates $(30 \mu \mathrm{m} / \mathrm{s}$ and $200 \mu \mathrm{m} / \mathrm{s}$, respectively). The change is approximately treated by using the onedimensional time-dependent diffusion equation:

$$
D_{s} \frac{\partial^{2} C(x, t)}{\partial x^{2}}=\frac{\partial C(x, t)}{\partial t}
$$

where $t$ is the evolution time, $x$ is the vertical distance from the boundary of the considered dendrite arm and its neighbor to the calculated location, and $C(x, t)$ is the concentration of $\mathrm{Al}$ at location $x$ and time $t$. What is the effect of $\mathrm{Nb}$ on the diffusion behavior of $\mathrm{Al}$ in $\beta$-Ti at high temperature is not clear. It is speculated that the effect of $\mathrm{Nb}$ is not considerable because $\mathrm{Nb}$ and $\mathrm{Ti}$ have the similar atomic size (atom radius of $\mathrm{Nb}$ is $1.46 \AA$ and atom radius of $\mathrm{Ti}$ is $1.47 \AA$ ) and $\mathrm{Nb}$ diffuses in titanium with the diffusion coefficient very near that for self-diffusion of $\mathrm{Ti}$ at high temperatures [26]. So, we consider $\mathrm{Al}$ as the solute and $\mathrm{Ti}$ $+\mathrm{Nb}$ as the solvent of the alloy, and the process is simplified down to a binary diffusion phenomenon.

The concentration distributions of $\mathrm{Al}$ in the primary dendrites do not happen to be sinusoidal. However, because the diffusion equation is linear, any number of similar equations can be added together, and according to Fourier analysis, any solute distribution can be described by a sum of a sine or cosine series and a constant. For the present problem, the simple sinusoidal concentration variation is quite useful because the higher-order terms decay much more rapidly than the longer ones, and the homogenization process will be ultimately determined by the relaxation time of the lowest-order term [23]. So the initial concentration variation of $\mathrm{Al}$ is approximately given by

$$
C(x, 0)=C_{0}+\delta C \cos \left(\frac{\pi x}{\lambda}\right)
$$

where $C_{0}$ is the average concentration of $\mathrm{Al}, \delta \mathrm{C}$ is the initial amplitude of the concentration variation at boundary of dendrite arms, and $\lambda$ is the primary dendritic arm spacing. The maximum concentration for the lowest-order term at $x=0, C^{\mathrm{m}}$, changes with time according to the following equation:

$$
C^{\mathrm{m}}(t)=C_{0}+\delta C \exp \left(-\frac{t}{\tau}\right)
$$

where $\tau=\lambda^{2} / \pi^{2} D_{s}$. Substitution of the corresponding experimental values (Table 1) into Equation (3) yields $\tau=$ $211.5 \mathrm{~s}$ and $D_{\mathrm{s}}=6 \times 10^{-11} \mathrm{~m}^{2} / \mathrm{s}$ for the $30 \mu \mathrm{m} / \mathrm{s}$ withdrawn
TABle 1: Values of physical parameters used for calculating diffusion coefficient and the results.

\begin{tabular}{lcccccc}
\hline$C_{0}($ at. $\%)$ & $C_{\mathrm{m}}$ & $\delta C($ at.\%) & $\lambda(\mathrm{m})$ & $\mathrm{T}(\mathrm{s})$ & $\tau(\mathrm{s})$ & $D_{\mathrm{s}}\left(\mathrm{m}^{2} / \mathrm{s}\right)$ \\
\hline 45.02 & 47.66 & 6.08 & $353 \times 10^{-6}$ & 167 & 211.5 & $6 \times 10^{-11}$ \\
44.88 & 45.81 & 3.53 & $144 \times 10^{-6}$ & 25 & 18.7 & $11 \times 10^{-11}$ \\
\hline
\end{tabular}

ingot and $\tau=18.7 \mathrm{~s}$ and $D_{\mathrm{s}}=11 \times 10^{-11} \mathrm{~m}^{2} / \mathrm{s}$ for the $200 \mu \mathrm{m} / \mathrm{s}$ withdrawn ingot. The increase of the value of $D_{\mathrm{s}}$ with the increase of solidification rate is because the contribution of the secondary dendrite to diffusion is ignored. The calculated $D_{s}$ is proportional to $\lambda^{2}$. If the contribution of the secondary dendrite to diffusion is considered, the average diffusion distance of $\mathrm{Al}$ decreases more significantly for higher rate withdrawn ingot because it has welldeveloped and finer secondary dendrite. Thus, the values of $D_{s}$ decrease correspondingly, and there should be a greater decrease for the $200 \mu \mathrm{m} / \mathrm{s}$ withdrawn ingot compared with the $30 \mu \mathrm{m} / \mathrm{s}$ withdrawn ingot. Maybe a complex correction for the calculation method results in two calculated values of $D_{s}$ quite according to each other.

The abovementioned diffusion behavior of $\mathrm{Al}$ takes place at the temperature near the solidus temperature of the alloy and within a temperature range of $21^{\circ} \mathrm{C}$, which can be obtained by the product of distance of the two sections $(5 \mathrm{~mm})$ in the same ingot and the temperature gradient $\left(4.2^{\circ} \mathrm{C} / \mathrm{mm}\right)$. Based on the thermodynamic database of Witusiewicz [25], we calculated the solidus temperature of Ti-45Al-8Nb alloy by Pandat software and obtained the value of $1530^{\circ} \mathrm{C}$. So we can say interdiffusion coefficient for $\mathrm{Al}$ in $\beta$-Ti is about $D_{\mathrm{s}}=(6 \sim 11) \times 10^{-11} \mathrm{~m}^{2} / \mathrm{s}$ at about $1530^{\circ} \mathrm{C}$. It is $4-11$ times higher than the results of Sung-Yul Lee determined by Matano's method for lower Al content $\beta$-Ti (about $D_{\mathrm{s}}=(1 \sim 1.5) \times 10^{-11} \mathrm{~m}^{2} / \mathrm{s}$ for Ti-(Ti-8.5 at.\% Al) couple) [27]. Apart from simplified calculation method, this is partly attributed to the higher $\mathrm{Al}$ content of the present alloy, for the value of $D_{\mathrm{s}}$ increases gradually with increasing aluminum content [27]. Although the values are semiquantitative results for neglecting $\mathrm{Nb}$ addition and considering solidification and cooling together, they have practical significance in designing heat treatment process to eliminate $\mathrm{Al}$ microsegregation for high $\mathrm{Nb}$-containing TiAl alloys.

\section{Conclusions}

Ti-45Al-8Nb alloy directionally solidified at temperature gradient of $4.2 \mathrm{~K} / \mathrm{mm}$ and withdrawing rate of $30 \mu \mathrm{m} / \mathrm{s}$ and $200 \mu \mathrm{m} / \mathrm{s}$, and the microstructures and the compositions of ingots were analyzed. The following conclusions can be drawn.

(1) Macrostructures show that both ingots are composed of columnar zone and dendritic zone, and the primary dendrite arm spacings are $353 \mu \mathrm{m}$ for the $30 \mu \mathrm{m} / \mathrm{s}$ withdrawn ingot and $144 \mu \mathrm{m}$ for the $200 \mu \mathrm{m} / \mathrm{s}$ withdrawn ingot, respectively. But the microstructures of the ingots are lamellar colonies, containing a few B2 patches and $\gamma$ bands. The $\gamma$ bands result from $\mathrm{Al}$ segregation during $\mathrm{L} \longrightarrow \beta$ 
solidification and the $\mathrm{B} 2$ patches result from $\mathrm{Nb}$ segregation during $\alpha \longrightarrow \alpha+\beta$ transformation. From dendritic zone to columnar zone, the B2 patches and $\gamma$ bands decrease.

(2) The segregation extents of $\mathrm{Al}$ and $\mathrm{Nb}$ decrease with the increase of solidification rate for the finer dendrite arm spacing is beneficial for diffusion of elements, and Al back diffusion during solidification and the diffusion during cooling after solidification is obvious. So, solidified ingots experience a homogenization process during their preparation.

(3) After simplifying down to a binary diffusion mode, a semiquantitatively calculated $\mathrm{Al}$ interdiffusion coefficient in $\beta$-Ti is $D_{s}=(6 \sim 11) \times 10^{-11} \mathrm{~m}^{2} / \mathrm{s}$ at near solidus temperature.

\section{Data Availability}

The measured data used to support the findings of this study are included within the supplementary information file.

\section{Conflicts of Interest}

The authors declare that there are no conflicts of interest regarding the publication of this paper.

\section{Acknowledgments}

This research was supported by the fund of the State Key Laboratory of Solidification Processing in NWPU (no. SKLSP201647), the National Natural Science Foundation of China (no. 51671016), and Henan Natural Science Foundation (no. 162300410342). The work was also supported by Chongqing Science and Technology Commission under the contract of cstc2018jcyjAX0727.

\section{Supplementary Materials}

The data are the original data used to plot Figure 6. Column 2 is the fraction solid, columns 3 through 6 are the $\mathrm{Al}$ contents for the four sections, and columns 7 through 10 are the $\mathrm{Nb}$ contents for the four sections, respectively. (Supplementary Materials)

\section{References}

[1] Z. C. Liu, J. P. Lin, S. J. Li, and G. L. Chen, "Effects of Nb and $\mathrm{Al}$ on the microstructures and mechanical properties of high Nb containing TiAl base alloys," Intermetallics, vol. 10, no. 7 , pp. 653-659, 2002.

[2] J. P. Lin, X. J. Xu, Y. L. Wang et al., "High temperature deformation behaviors of a high $\mathrm{Nb}$ containing TiAl alloy," Intermetallics, vol. 15, no. 5-6, pp. 668-674, 2007.

[3] J. Li, Y. Liu, B. Liu, Y. Wang, X. Liang, and Y. He, "Microstructure characterization and mechanical behaviors of a hot forged high $\mathrm{Nb}$ containing PM-TiAl alloy," Materials Characterization, vol. 95, pp. 148-156, 2014.

[4] M. Kastenuber, B. Rashkova, H. Clemens, and S. Mayer, "Enhancement of the application temperature of titanium aluminides," BHM, vol. 160, no. 7, pp. 342-345, 2015.
[5] G. Chen, Y. Peng, G. Zheng et al., "Polysynthetic twinned TiAl single crystals for high-temperature applications," Nature Materials, vol. 15, no. 8, pp. 876-881, 2016.

[6] J. P. Lin, L. L. Zhao, G. Y. Li et al., "Effect of $\mathrm{Nb}$ on oxidation behavior of high $\mathrm{Nb}$ containing TiAl alloys," Intermetallics, vol. 19, no. 2, pp. 131-136, 2011.

[7] B. P. Bewlay, S. Nag, A. Suzuki, and M. J. Weimer, "TiAl alloys in commercial aircraft engines," Materials at High Temperatures, vol. 33, no. 4-5, pp. 549-559, 2016.

[8] Y. W. Kim and S. L. Kim, "Advances in gammalloy materials-processes-application technology: successes, dilemmas, and future," JOM, vol. 70, no. 4, pp. 553-560, 2018.

[9] X. J. Xu, J. P. Lin, and D. D. Han, "Effect of $\mathrm{Al}$ on microstructures and properties of Ti-45Al-8.5Nb-0.2B-0.2W alloy," Materials Science Forum, vol. 747-748, pp. 44-49, 2013.

[10] L. Song, L. Q. Zhang, X. J. Xu, J. Sun, and J. P. Lin, "Omega phase in as-cast high-Nb-containing TiAl alloy," Scripta Materialia, vol. 68, no. 12, pp. 929-932, 2013.

[11] Z. W. Huang, W. Voice, and P. Bowen, "Thermal exposure induced $\alpha_{2}+\gamma \longrightarrow \mathrm{B} 2(\omega)$ and $\alpha_{2} \longrightarrow \mathrm{B} 2(\omega)$ phase transformations in a high $\mathrm{Nb}$ fully lamellar TiAl alloy," Scripta Materialia, vol. 48, no. 1, pp. 79-84, 2003.

[12] O. Shuleshova, D. Holland-Moritz, W. Löser et al., "In situ observations of solidification processes in $\gamma$-TiAl alloys by synchrotron radiation," Acta Materialia, vol. 58, no. 7, pp. 2408-2418, 2010.

[13] X. F. Ding, J. P. Lin, L. Q. Zhang, Y. Q. Su, and G. L. Chen, "Microstructural control of TiAl-Nb alloys by directional solidification," Acta Materialia, vol. 60, no. 2, pp. 498-506, 2012.

[14] M. Oehring, A. Stark, J. D. H. Paul, T. Lippmann, and F. Pyczak, "Microstructural refinement of boron-containing $\beta$-solidifying $\gamma$-titanium aluminide alloys through heat treatments in the $\beta$ phase field," Intermetallics, vol. 32, pp. 12-20, 2013.

[15] T. Klein, S. Niknafs, R. Dippenaar, H. Clemens, and S. Mayer, "Grain growth and $\beta$ to $\alpha$ transformation behavior of a $\beta$ Solidifying TiAl alloy," Advanced Engineering Materials, vol. 17, no. 6, pp. 1-5, 2014.

[16] Z. Zollinger, V. Witusiewicz, A. Drevermann, D. Daloz, and U. Hecht, "Solidification of high Nb containing TiAl based alloys," International Journal of Cast Metals Research, vol. 22, no. 1-4, pp. 339-342, 2009.

[17] X. Xu, L. Song, X. Jin, D. Han, X. Wang, and J. Lin, "Microstructure and microsegregation of directionally solidified $\mathrm{Ti}-45 \mathrm{Al}-8 \mathrm{Nb}$ alloy with different solidification rates," Rare Metals, vol. 35, no. 1, pp. 70-76, 2016.

[18] M. Ganesan and D. Dye, "A technique for characterizing microsegregation in multicomponent alloys and its application to single-crystal superalloy castings," Metallurgical and Materials Transactions A, vol. 36, no. 8, pp. 2191-2204, 2005.

[19] L. Song, X. J. Xu, J. Sun, and J. P. Lin, "Cooling rate effects on the microstructure evolution in the $\beta_{0}$ zones of cast $\mathrm{Ti}-$ 45Al-8.5Nb-(W, B, Y) alloy," Materials Characterization, vol. 93, pp. 62-67, 2014.

[20] C. Zhang, D. Ma, S. Kou, Y. A. Chang, and X. Y. Yan, "Microstructure and microsegregation in directionally solidified Mg-4Al alloy," Intermetallics, vol. 15, no. 10, pp. 1395-1400, 2007.

[21] J. D. Hunt and S. Z. Lu, "Numerical modeling of cellular/ dendritic array growth: spacing and structure predictions," Metallurgical and Materials Transactions A, vol. 27, no. 3, pp. 611-623, 1996. 
[22] A. F. Ferreira, J. A. Castroa, and L. O. Ferreira, "Predicting secondary-dendrite arm spacing of the $\mathrm{Al}-4.5 \mathrm{wt} \% \mathrm{Cu}$ alloy during unidirectional solidification," Materials Research, vol. 20, no. 1, pp. 1-8, 2017.

[23] W. Kurz and D. J. Fisher, Fundamentals of Solidification, Trans tech publications Ltd., Aedermannsdorf, Switzerland, 3rd edition, 1992.

[24] R. G. Santos and M. L. N. M. Melo, "Permeability of interdendritic channels," Materials Science and Engineering: A, vol. 391, no. 1-2, pp. 151-158, 2005.

[25] V. T. Witusiewicz, A. A. Bondar, U. Hecht, and T. Y. Velikanova, "The Al-B-Nb-Ti system: IV. Experimental study and thermodynamic re-evaluation of the binary $\mathrm{Al}-\mathrm{Nb}$ and ternary Al-Nb-Ti systems," Journal of Alloys and Compounds, vol. 472, no. 1-2, pp. 133-161, 2009.

[26] A. E. Pontau and D. Lazarus, "Diffusion of titanium and niobium in bcc Ti-Nb alloys," Physical Review B, vol. 19, no. 8 , pp. 4027-4037, 1979.

[27] S. Y. Lee, O. Taguchi, and Y. Iijima, "Diffusion of aluminum in $\beta$-titanium," Materials Transactions, vol. 51, no. 10, pp. 1809-1813, 2010. 


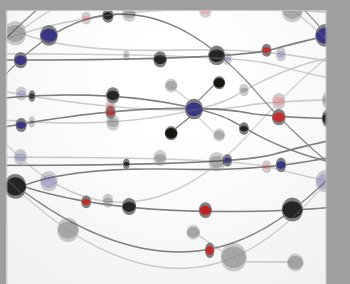

The Scientific World Journal
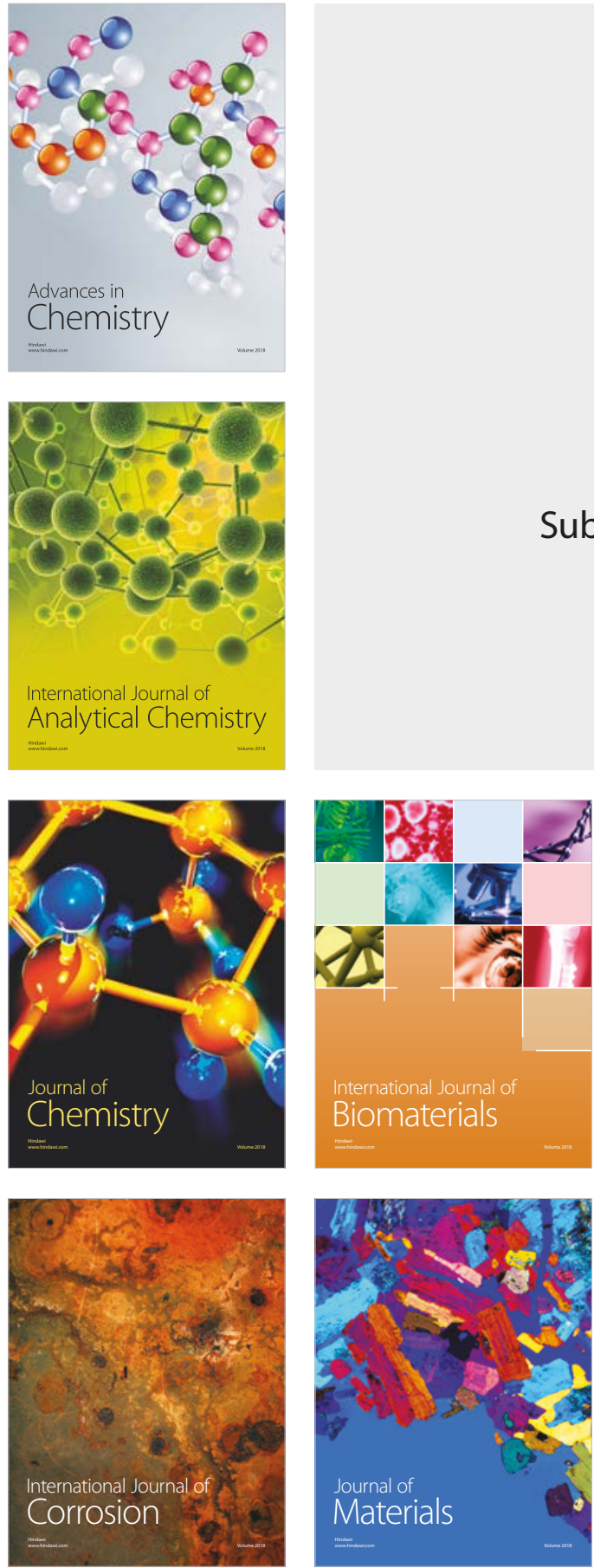

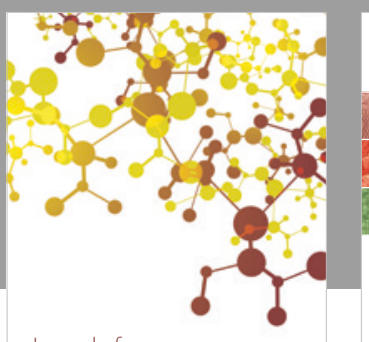

Journal of

Applied Chemistry
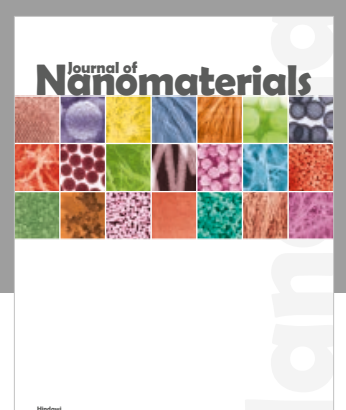

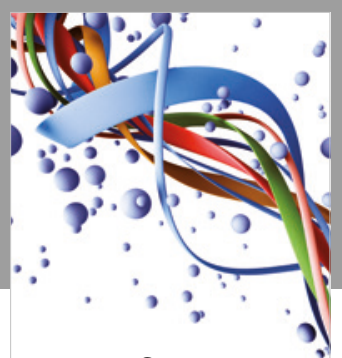

Scientifica

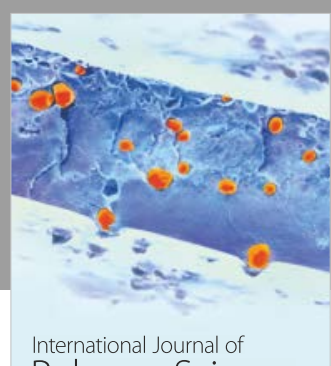

Polymer Science

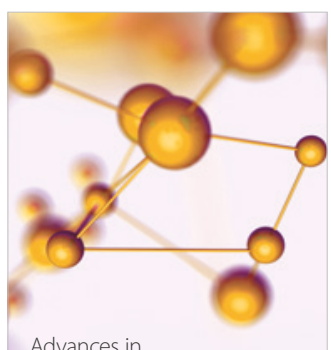

Physical Chemistry
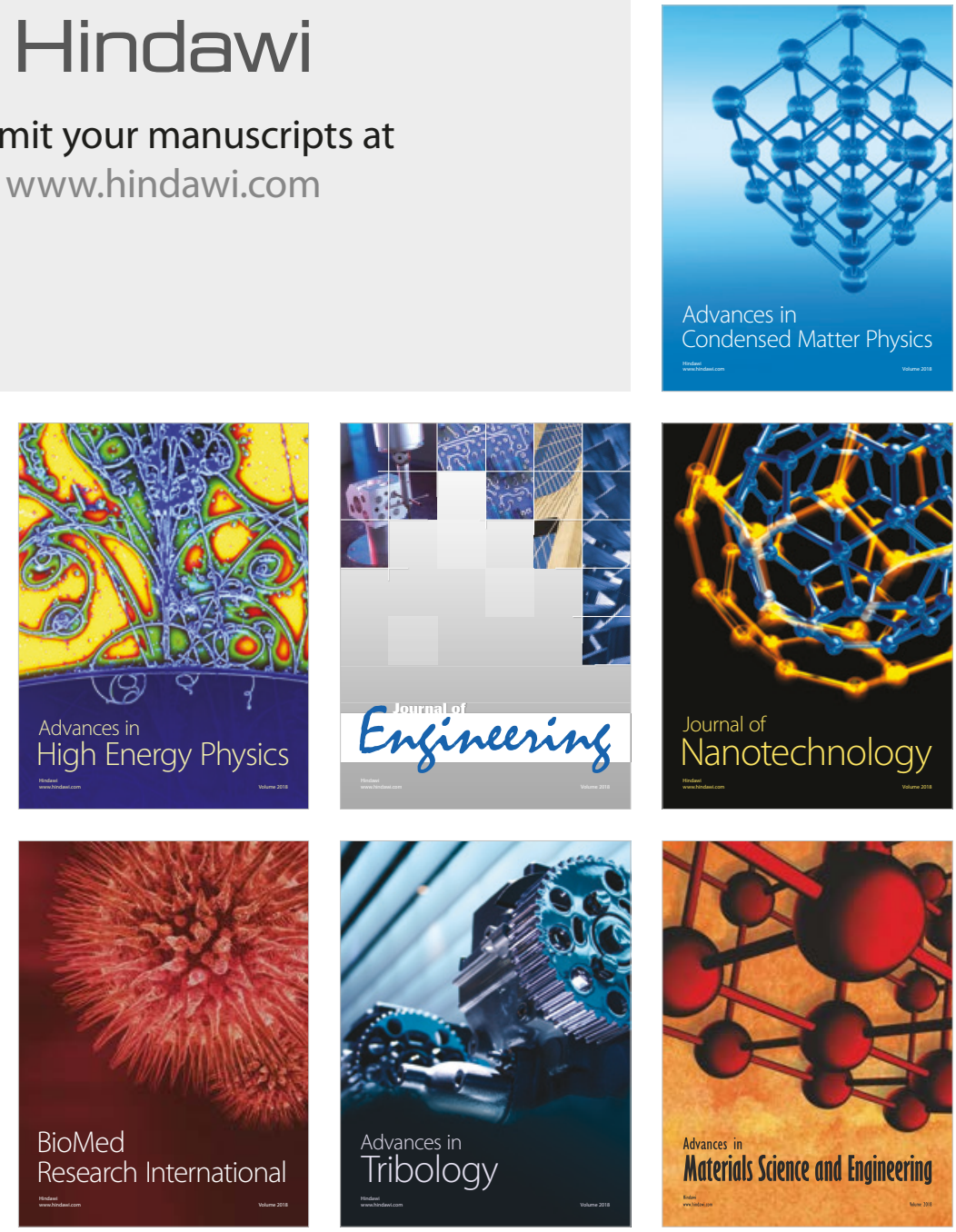